\section{International Scientific Journal Theoretical \& Applied Science}

p-ISSN: 2308-4944 (print)

e-ISSN: 2409-0085 (online)

Year: $2014 \quad$ Issue: $12 \quad$ Volume: 20

Published: $30.12 .2014 \quad$ http://www.T-Science.org

SECTION 8. Architecture and construction.
Aleksey Robizonovich Burduladze

Doctor of technical Sciences, Professor national defence Academy of Georgia, Georgia burdato@yahoo.com

Malkhaz Georgievych Bezhanishvili Doctor of technical Sciences, Professor Georgian technical University, Georgia malxobe@yahoo.com

Manuchar Tamazovich Shishinashvili Doctor of engineering Sciences, Professor national defence Academy of Georgia, Georgia m.shishinashvili@gmail.com

\title{
EXISTING IN GEORGIA LOCAL ROAD CONSTRUCTION MATERIALS AND THEIR OPTIMAL USE IN THE CONSTRUCTION OF PAVEMENT
}

Abstract: The questions about the use of local stone materials in road construction in Georgia. It is said that one of the main causes of intense deformation and wear coating is the massive use of crushed gravel obtained from local quarries, which requires solving a number of problems in the nature of the problem.

The article marked that the use of gravel, in order to ensure the sustainability of a shift of the most promising is the introduction of small amounts of cement in the non-rigid pavements. Such semi-rigid pavement is designed in Georgian Technical University.

The article raised the question of what to supply road construction Georgian stone materials is very important to the discovery and creation of basic quarries there plants for the production of rubble that will enable centralized supply of high-quality road construction rubble, and that the creation of a basic career when choosing metorozhdeniya preference should be given to the deposits that are relatively close in terms of transporting goods will be more profitable.

Key words: local stone material, crushed gravel, basic career, whin strins.

Language: Russian

Citation: Burduladze AR, Bezhanishvili MG, Shishinashvili MT (2014) EXISTING IN GEORGIA LOCAL ROAD CONSTRUCTION MATERIALS AND THEIR OPTIMAL USE IN THE CONSTRUCTION OF PAVEMENT. ISJ Theoretical \& Applied Science 12 (20): 61-64. doi:

http://dx.doi.org/10.15863/TAS.2014.12.20.14

\section{СУЩЕСТВУЮЩИЕ В ГРУЗИИ МЕСТНЫЕ ДОРОЖНЫЕ СТРОИТЕЛЬНЫЕ МАТЕРИАЛЫ И ИХ ОПТИМАЛЬНОЕ ИСПОЛЬЗОВАНИЕ В КОНСТРУКЦИЯХ ДОРОЖНОЙ ОДЕЖДЫ}

Аннотация: В статье рассмотрены вопросы об использования местных каменных материалов 6 дорожном строчтельстве Грузии. Сказано, что одна из основных причин возникновения деформаџий и интенсивного износа покрытия является массовое использование дробленого гравия, полученного с местных карьеров, а это требует решения целого ряда задач проблемного характера.

В статье отмеченно, что при использовании гравийного материала, с целью обеспечения устойчивости к сдвигу наиболее перспективным является внесение небольших добавок цемента в нежесткие дорожные покрытия. Такое полужесткое дорожное покрытие разработано в Грузинском техническом университете.

В статье поставлен вопрос, что для снабжения дорожного строительства Грузии каменными материалами весьма важным является открытие базисных карьеров и создание там заводов по производству щчебня, что сделает возможным иентрализованное снабжение дорожного строительства высококачественным цеебне, и что для создания базисного карьера при выборе меторождения предпочтение нужно отдать тем месторождениям, которые расположены сравнительно близко и с точки зрения транспортирования продукции будут более выгодными.

Ключевые слова: местные каменные материали, дробленый гравий, базисные карьеры, прочность пород.

При конструировании дорожной одежды особое внимание уделяется использованию местных каменных материалов. Известно, что территория Грузии богата каменными

ISPC European Research,

материалами, однако они в основном низкого качества и их использование в дорожном строительстве зачастую не приносит хорошего результата. 
На многих участках наших дорог и улиц, в условиях высоких скоростей и интенсивного движения состояние дорожного покрытия не обеспечивает нормальное функционирование транспортного потока. Опыт свидетельствует о том, что в условиях мягкого климата и гористого рельефа Грузии на больших уклонах, на поворотах, в местах остановок интенсивное действие сил торможения и тяги автомобиля негативно влияет на состояние дорожного покрытия. Поэтому на нежестких покрытиях массово возникают деформации сдвига, вследствие чего дорожное покрытие интенсивно изнашивается и разрушается, увеличиваются дорожные эксплуатационные расходы, уменьшается долговечность покрытия, ухудшается безопасность и условия движения транспортных средств, становится необходимым систематический ремонт проезжей части дороги, устройство дополнительных слоев на деформированном слое, что в результате приводит к чрезмерному увеличению толщины покрытий.

Одна из основных причин возникновения деформаций и интенсивного износа покрытия является массовое использование дробленого гравия, полученного с местных карьеров. Эта традиция укоренилась давным давно и в определенном смысле была оправданна на ранних этапах развития транспорта, когда интенсивность и скорость движения были гораздо ниже.

Общая протяженность автомобильных дорог международного и внутригосударственного назначения в Грузии с 3200 км (на 1938 год) увеличилась на сегодняшний день почти вдвое. Соответственно, выросло количество покрытий улучшенного типа. В этот же период почти в 15 и даже более раз увеличилась сеть дорожных дорог. Еще более значительные сдвиги ожидаются в этом направлении в будущем. Согласно плану перспективного развития дорожной сети Грузии на ближайшее будущее предусмотрено увеличение на 3000 километров общей протяженности дорог международного и внутригосударственного назначения. В Тбилиси генеральный план реконструкции предусматривает значительное расширение сети дорожных дорог. Большие перспективы открываются также и перед другими городами.

Все это требует решения целого ряда задач проблемного характера. С одной стороны, в дорожное строительство должны быть внедрены такие конструкции дорожного покрытия, которые, в условиях использования полученного с местных карьеров гравийного материала, максимально обеспечат соответствующую прочность дорожного покрытия относительно деформаций сдвига. С другой стороны, с целью получения износоустойчивости и создания шероховатых поверхностей, во всех случаях дробленый гравий должен быть заменен в поверхностных слоях дорожного покрытия на щебень, изготовленный из высокопрочных пород.

При использовании гравийного материала, с целью обеспечения устойчивости к сдвигу наиболее перспективным является внесение небольших добавок цемента в нежесткие дорожные покрытия. От усовершенствованных покрытий такого типа определенным техникоэкономическим преимуществом отличается полужесткое дорожное покрытие, которое разработано в Грузинском техническом университете.

Полужесткое покрытие представляет собой покрытие, созданное из битум-минеральной системы, в которое включен промежуточный, тонкий жесткий слой из песочно-цементного раствора. Такой жесткий слой выполняет роль скелета (остова), резко увеличивает конструктивную жесткость покрытия и устойчивость к деформации сдвига.

Полужесткое покрытие обходится дешевле асфальтобетонного покрытия той же толщины, в то же время его прочность в несколько раз превышает прочность асфальтобетонного покрытия. Особенностью его покрытий является то, что в горизонтальном направлении они работают как жесткие бетонные покрытия, а в вертикальном направлении - как нежесткие асфальтобетонные покрытия. Их техническое примущество было подтверждено практическим использованием и соответствующим расчетом устойчивости тонких плит к продольному изгибу. Показателем экономического преимущества является то, что в полужестких покрытиях возможно широкое использование гравийного материала низкой прочности в натуральном виде или переработанного в щебень, а также других некондиционных каменных материалов, использование которых, как неустойчивых к сдвигу материалов запрещено нормативнотехнической документацией.

С целью еще большего увеличения устойчивости к сдвигу в полужестких дорожных одеждах, наряду с устройством промежуточного жесткого слоя, целезообразно уменьшить на 1$1,5 \%$ количество битума, по сравнению с оптимальным количеством, предусмотренным техническими условиями. Уменьшение количества битума уменьшает пластичность покрытий и, соответственно, повышает устойчивость к сдвигу, однако, в то же время, усиливает износ покрытий. Во избежание этого негативного явления необходимо нанести на такие покрытия поверхностный износостойкий и водонепроницаемый защитный слой. 
В битумно-минеральных системах уменьшение количества битума связано с необходимостью увеличения качества трамбования покрытий. Нанесение износостойкого, водонепроницаемого поверхностного слоя и максимальное трамбование - те основные факторы, которые обеспечивают компенсацию негативных последствий уменьшения количества битума. Уменьшение количества битума в покрытиях, наряду с техническими преимуществами, связано со значительным экономическим эффектом экономией битума, чему на современном этапе придается государственное значение.

При технико-экономическом сравнении различных вариантов полужесткого дорожного покрытия предпочтение должно быть отдано тому из вариантов с одинаковой прочностью, в котором для устройства жесткого промежуточного слоя максимально будет использован гравийный материал.

На сегодняшний день дорожное строительство страны практически полностью снабжается каменными материалами с карьеров местного гравия. Эти карьеры в виде предприятий небольшой мощности разбросаны по всей территории Грузии и служат интересам отдельных дорожных объектов. Сегодняшние организационные формы обработки карьеров не являются эффективными и требуют коренной перестройки. Многолетний опыт показывает, что для снабжения дорожного строительства каменными материалами весьма важным является открытие базисных карьеров и создание там заводов по производству щебня, что сделает возможным централизованное снабжение дорожного строительства высококачественным щебнем.

Создание базисных карьеров и заводов по производству щебня положительно повлияет на многие факторы дорожного строительства. С использованием высококачественного щебня улучшатся транспортно-эксплуатационные показатели дорожных покрытий, повысится продолжительность работы покрытий, уменьшатся эксплуатационные расходы, в результате чего существенно повысится уровень эффективности дорожного строительства, будут созданы условия для массового внедрения шероховатых покрытий, создана возможность для полноценного изучения свойств щебня, полученного централизованным путем с точки зрения его использования в дорожных покрытиях, в различных климатических условиях. Это весьма важное обстоятельство, поскольку прежняя советская техническая документация не обеспечивала правильную оценку качества местного каменного материала. Более полное изучение свойств щебня позволит нам значительно уменьшить объем геологопоисковых работ с целью определения каменных материалов, необходимых для строительства автомобильных дорог, особенно в районах Черноморского побережья, в некоторых зонах которого с целью охраны природы уже длительное время запрещена эксплуатация песчано-гравийных карьеров и вывоз материала. Значительно улучшатся природоохранные и экологические условия. Создание базисных карьеров даст нам возможность максимальной механизации и автоматизации процессов добычи и обработки камня.

Базисные карьеры и заводы по производству щебня целесообразно создавать на базе месторождений извергаемых пород (для изнашиваемых слоев) и на базе месторождений качественного гравийного материала (для всех других конструкционных слоев покрытия). Во всех других конструкционных слоях дорожного покрытия возможно использование гравийного материала, полученного с местных карьеров. Только таким путем станет возможно повышение качества дорожной сети Грузии до уровня мировых стандартов.

Вычислениями подтверждается, что на территории Грузии с технико-экономической точки зрения более целесообразно создание двух базисных карьеров (один в Восточной Грузии, второй - в Западной Грузии) на базе месторождений извергаемых крепких пород. Наряду с карьерами должны быть построены соответствующие заводы по производству щебня. Кроме этого, необходимо создать два базисных карьера на базе месторождений известняка. На этих карьерах будет основано производство известнякового щебня и минерального порошка.

С целью полного учета дорожностроительных материалов, распространенных на территории Грузии, нами была собрана информация, имеющаяся во всех тех проектных, строительных и геологических организациях, которые ищут и исследуют месторождения каменных материалов. На основании этого материала составлены карты распределения дорожно-строительных каменных материалов на территории Грузии. На первой карте приведены 216 месторождений извергаемых, осажденных и метаморфических скальных пород, а на второй 328 месторождений песка-гравия.

Из 148 месторождений скальных пород (за исключением карбонатных пород) 98 расположены в Западной Грузии, а 50 - в Восточной Грузии. 60 процентов этих месторождений содержат породы, порог прочности которых меньше 120 МПа.

Месторождения скальных пород, которые относятся ко второму классу пород первой и второй группы, в основном сосредоточены в 
высокогорных районах южного склона Большого Кавказского хребта, в кристальном массиве реки Дзирула и в южной части Малого Кавказского хребта. Связаться с ними можно только автомобильными дорогами четвертой-пятой категории, которые в основном расположены в горном рельефе и зимой становятся труднопроходимыми. Запасы некоторых таких месторождений весьма малы и очень изменчивы по прочности пород. Вследствие этого из этих месторождений для создания базисных карьеров приемлемыми оказались только 5, прочность пород которых превышала $120 \mathrm{MПа,} \mathrm{а} \mathrm{марка} \mathrm{по}$ износу - и-25. На их базе можно создать карьерное хозяйство и построить за год заводы по производству щебня производительностью как минимум до $50000 \mathrm{~m}^{3}$.
Для создания базисного карьера при выборе меторождения предпочтение нужно отдать тем месторождениям, которые расположены сравнительно близко и с точки зрения транспортирования продукции будут более выгодными. Например, для Западной Грузии с этой целью предпочтение отдается Опурчхетскому месторождению тешенита, впрочем здесь нужно учесть то обстоятельство, что завод по производству щебня будет перерабатывать только отходы производства облицовочных каменных плит. То же самое можно сказать о Телованском андезитнобазальтовом месторождении в Восточной Грузии. Общая технологическая схема переработки пород в щебень на этих карьерах и заводах должна быть устроена на современном уровне развития техники.

\section{References:}

1. Burduladze A, Shishinashvili M, Magradze M, Bakuradze T (2014) PERSPECTIVES OF USE OF COLD RECYCLING IN THE ROAD SECTOR OF GEORGIA. IHJVT $<$ B TRANSACTIONS TRUDY, 113.

2. Shishinashvili M (2014) ASPHALT SURFACE RECYCLING ACCORDING TO THE HOT METHOD. inteleqtuali, 148.

3. Burduladze AR, Shishinashvili MT, Magradze MD (2014) IMPROVEMENT OF THE QUALITY OF THE ASPHALT MIX. ISJ Theoretical \& Applied Science, 02 (10): 44-47. doi:

http://dx.doi.org/10.15863/TAS.2014.02.10.7

4. Burduladze A, Maghradze M, Gabunia D, Kachiuri B, Bakuradze T (2014) WEAR-RESISTANCE OF ASPHALT CONCRETE ROAD COVER. IHJVT $<\mathrm{B}$ TRANSACTIONS TRUDY, 76.

5. Seaman, Harry J (1946) "Road building machine." U.S. Patent No. 2,394,017. 5 Feb. 1946.

6. Webster, Steve L (1979) Investigation of Beach Sand Trafficability Enhancement Using Sand-
Grid Confinement and Membrane Reinforcement Concepts. Report 1. Sand Test Sections 1 and 2. No. WES/TR/GL-79-20. ARMY ENGINEER WATERWAYS EXPERIMENT STATION VICKSBURG MS GEOTECHNICAL LAB, 1979.

7. Wedding, Presley A, Richard D Gaynor (1961) "THE EFFECTS OF USING CRUSHED GRAVEL AS THE COARSE AND FINE AGGREGATE IN DENSE GRADED BITUMINOUS MIXTURES (WITH DISCUSSION)." Association of Asphalt Paving Technologists Proceedings. Vol. 30. 1961.

8. Smith Mick R, Laurence Collis, PG Fookes, etc. (2001) "Aggregates: sand, gravel and crushed rock aggregates for construction purposes." Geological Society of London, 2001.

9. Javed Sayeed, CW Lovell, Leonard E (1994) Wood. "Waste foundry sand in asphalt concrete." Transportation research record 1437.

10. Asi Ibrahim M, etc. (2002) "Stabilization of dune sand using foamed asphalt." ASTM geotechnical testing journal 25.2: 168-176. 